\title{
Kriminal İnceleme İçin Vücut Sıvılarının Zamana Bağlı Değişiminin Hiperspektral Görüntüleme İle Belirlenmesi
}

\author{
Rıdvan Safa Hatipoğlu ${ }^{1 *}$, Süleyman Canan ${ }^{2}$, Murat Ceylan ${ }^{3}$ \\ ${ }^{1}$ Elfatek Elektronik Makina Ve Otom. San. Ve Tic. Ltd. Şti, Konya, Türkiye (ORCID: 0000-0002-4357-1829) \\ ${ }^{2}$ Elfatek Elektronik Makina Ve Otom. San. Ve Tic. Ltd. Şti, Konya, Türkiye ORCID: 0000-0001-5842-5683) \\ ${ }^{2}$ Konya Teknik Üniversitesi, Elektrik Elektronik Mühendisliği Bölümü, Konya, Türkiye (ORCID: 0000-0001-6503-9668)
}

( $1^{\text {st }}$ International Conference on Computer, Electrical and Electronic Sciences ICCEES 2020 - 8-10 Ekim 2020)

(DOI: 10.31590/ejosat.803377)

ATIF/REFERENCE: Hatipoğlu, R.S., Canan, S. \& Ceylan, M. (2020). Kriminal İnceleme İçin Vücut Sıvılarının Zamana Bağlı Değişiminin Hiperspektral Görüntüleme İle Belirlenmesi. Avrupa Bilim ve Teknoloji Dergisi, (Özel Say1), 148-153.

\section{Öz}

Hiperspektral görüntüleme yöntemleri askeri uygulamar, kimyasal analizler, tarım alanı analizeleri gibi birçok alanda kullanılmaktadır. Görüntünün kaydedilmesi esnasında her piksel değerine objeden yansıyan ışığın dalga boyları kaydedilerek oluşturulan matris verileri ile hipersipektral görüntü elde edilmektedir. Hiperspektral görüntüleme ile görünür dalga boyu (400$700 \mathrm{~nm}$ ) haricinde kızıl ötesi gibi diğer dalga boylarına ait veriler de elde edilmektedir. Bu veriler yardımı ile spektral imzalar elde edilmektedir. Hiperspektral görüntüleme uygulamaları çoğunlukla görünür ışıkta aynı renge sahip birbirine karışmış birçok bileşenin ayırt edilmesinde kullanılmaktadır. Bu çalışamda genel kullanınım aksine, hiperspektral görüntüleme yöntemi nesnelerin spektral imzasının zamanla değişimini konu almaktadır.

Kriminal incelemelerde kullanılan görüntüleme yöntemi RGB kameralar ile sağlanmakta ve olay yerine ait incelemeler bu görüntüler üzerinden yapılmaktadır. Olay yerinden alınan görüntülerin laboratuvar ortamında incelenmektedir. Laboratuvar ortamında incelenmesi yerine taşınabilir bir sistemle olay yerinde inceleme ve sonuç elde etmeye yönelik yapılan bu çalışmada numunelerin zaman bilgileri tespit edilmesi hedeflenmiş̧ir. Buradaki zaman bilgisi, olayın meydana geliş süresini analiz etmeyi içermektedir. Bu çalışmada ortam aydınlatması için halojen lamba, görüntü kaydı için 400-100 nm dalga boylarında görüntü kaydı yapan hiperspektral kamera kullanılmıştır. Hiperspekral kamera ile elde edilen olay yerindeki vücut kalıntılarının (kan, tükürük, idrar) spekral imazaları elde edilmiştir. İlgili alana ait temiz yüzeyden alınan spektral imza ile karşılaştırılarak elde edilen zamana bağlı değişim grafiklerindeği yoğunluk değerleri, vücut kalıntılarının olay yerinde ne kadar zamandır kaldığına dair bilgileri barındırdırdığı görülmüştür.

\section{Determination of Time-Dependent Changes of Body Fluids Using Hyperspectral Imaging for Criminal Examination}

\begin{abstract}
Hyperspectral imaging methods are used in many fields such as military applications, chemical analysis, agricultural field analysis. While recording the image, wavelengths of light reflected from the object are recorded for each pixel value. Hypersipectral images are obtained with the matrix data created after recording. In addition to the visible wavelength (400-700nm), data of other wavelengths such as infrared are also obtained with hyperspectral imaging. Spectral signatures are obtained with the help of these data. Hyperspectral imaging applications are mostly used to distinguish many intermixed components with the same color in visible light.
\end{abstract}

\footnotetext{
* Sorumlu Yazar Elfatek Elektronik Makina Ve Otom. San. Ve Tic. Ltd. Şti, Konya, Türkiye, ORCID: 0000-0002-4357-1829, 
In this study, the hyperspectral imaging method, contrary to its general use, is about the change in the spectral signature of objects over time.

The imaging method used in criminal investigations is provided by RGB cameras and the investigations of the scene are made with these images. The images obtained from the crime scene are analyzed in the laboratory environment. It is aimed to determine the time information of the samples in this study, which was carried out to examine the scene and obtain results with a portable system instead of being examined in a laboratory environment. The time information here includes analyzing the occurrence time of the event. In this study, a halogen lamp was used for ambient lighting, and a hyperspectral camera recording images at 400-100 nm wavelengths was used for image recording. Specral imprints of body remains (blood, saliva, urine) at the scene obtained by the hyperspecral camera were obtained. The density values in the time-dependent graphs obtained by comparing with the spectral signature taken from the clean surface of the relevant area, the information about how long the body remains remained at the scene. It has been seen to host.

Keywords: Hyperspectral Imaging, Forensic Imaging, Criminal Imaging

\section{Giriş}

Hiperspektral (HS) görüntüleme; arkeoloji ve sanat eserlerini koruma (Fischer ve Ark., 2006; Liang ve Ark., 2012), yöntemleri bitki örtüsü ve su kaynakları sağlığ1 (Govender ve Ark.,2007; Adam ve Ark. 2010), gida sağlığ1 ve kalitesi (Gowen ve Ark., 2007; Feng ve Ark., 2012), adli tıp )Edelman ve Ark., 2012; Edelman ve Ark., 2012; Malkoff ve Ark., 2000), olay yeri inceleme (Kuula ve Ark., 2012; Schuler ve Ark., 2012), biyomedikal (Carrasco ve Ark., 2003; Afromowitz ve Ark., 1988) gibi birçok alanda kullanılmaktadır. Görüntünün kaydedilmesi esnasında her piksel değerine objeden yansıyan 1şı̆̆ın dalga boyları kaydedilerek oluşturulan matris verileri ile hipersipektral görüntü elde edilmektedir. Hiperspektral görüntüleme ile görünür dalga boyu (400-700nm) haricinde k1z1l ötesi gibi diğer dalga boylarına ait veriler de elde edilmektedir. Buna bağlı olarak ilgili alana ait dalgaboyu yoğunluk grafikleri oluşuturulmaktadır. Bu dalga boyu grafiklerine "spekral imza" ismi verilmektedir. Her objenin ilgili alanına ait spectral imzası farklılık göstermektedir. Bu sayede nesnelerin spectral imzalarına bakılarak nesne ayrımı oldukça kolaylaşmaktadır.

Hiperspektral görüntüleme yöntemi, gözle ayırt edilmesi zor ve aynı renge ait nesnelerin karışımının olduğu uygulamarda nesneleri ayırt etmek için de kullanılmaktadır (Fei, 2020). Bu çalışmanın araştırma konusu ise hipersprekral görüntüleme sonucu elde edilen veriler kullanılarak spekral imzaların zaman bağlı değişiminin incelenmesidir. Buna bağlı olarak adli tıp çalışanlarının olay yeri ile ilgili aldıkları örneklerin zaman ile ilişkilerini tespit etmek için bir yöntem geliştirilmiştir.

Adli tıp çalışanları olay yerindeki vücut kalıntılarına ait bilgileri geleneksel kamera kayıt yöntermleri ile görüntülemektedirler. Bu kalıntılara ait görüntüleri laboratuvar ortamında inceleyerek olay ile ilgili bazı ipuçları bulmaktadırlar. Normal kameralar ile alınan bu görüntüler ile olayın meydana gelme zamanı tahmin edilememektedir. Bu çalışma ile adli tıp çalışanlarının olay yerine ulaştıkları esnada taşınabilir bir sistem ile numunelere ait aldıkları hiperspektral görüntüler ile vücut kalıntılarının ne zamandan beri o bölgede olduğuna dair bilgi edinilmesi hedeflenmiştir. Görüntü alınması sonrası laboratuvar ortamına veriler taşınmadan, olay yerinde hızlı bir şekilde sonuç veren bu sistemde kan, idrar ve tükürük örnekleri kumaş üzerine sıçradığı varsayılarak hiperspektral görüntüleri alınmış ve zamana bağlı olarak değişimleri, geliştirilen yazılım ile analiz edilmiştir.

\section{Materyal ve Metot}

Hiperspektral görüntülerin alınması için Specim firmasının ürettiği Specim IQ kamera kullanılmıştır. Bu kamera ile karanlık ortamda halojen lambanın aydınlattığı objelerin görüntüsü 400-1000 nm dalgaboyları arasında elde dilmiştir. Ayıca 204 adet spektral bandın bulunduğu bu kamera 512×512 piksel çözünürlükte görüntü kaydı yapabilmektedir.

\subsection{Deney Düzeneği}

Deney düzeneği Şekil 1'de bulunan hiperspektal kamera, halojen lamba ve kumaş üzerine damlatılmış kan, tükürük ve idrar örneklerinden oluşmaktadır. Vücut kalıntılarının damlatıldığı kumaşın belli aralıklar ile görüntüleri alınarak kaydedilmiştir.

Kurulan deney düzeneğindeki zamana bağlı değişimin net olarak tespit edilebilmesi için objeler karanlık ortamda halojen lamba kullanılarak aydınlatılmışır. Böylece sabit ışık şiddeti altındaki kan, tükürük ve idrar örneklerinin kumaş üzerindeki değişimi aynı şartlar altında incelenebilmiştir.

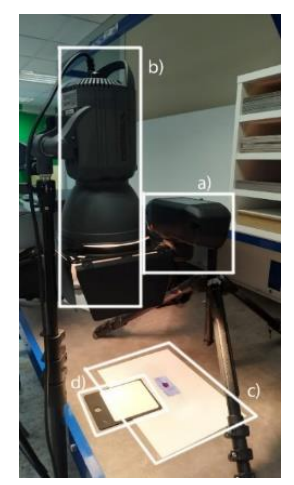

Şekil 1. Çalışmada Kullanılan Deney Düzeneği a) Hiperspeltral kamera, b) Halojen lamba, c) Görüntüsü alıncak bölge, d) Hiperspektral beyaz referans plaketi 


\subsection{Zaman Analiz Algoritmast}

Adli tıp personeli olay yerine ulaştığı anda aldığı hiperspektral görüntüler vücut kalıntılarının o anki durumlarını göstermektedir ve analiz işlemi de buna göre değerlendirilmelidir. Bu sebepten kalıntılara ait zaman tespiti yaparken kumaşın görüntü alındığı andaki lekesiz bir bölümü ve lekeli bölge kullanılmıştır. Uygulanan yönteme Şekil 2'de görülmektedir. Bu kısımda RGB görüntü üzerinde seçilen ilgili alanın spekral imza ortalaması, kaydedilen hiperspektral görüntüden elde edilmiştir. Temiz kumaş parçasına ait elde edilen spektral imza yoğunluğundan lekeli alana ait spektral imza yoğunluğu çıkarılmıştır. Her görüntü için önce lekesiz alan belirlenmiş daha sonra lekeli alan belirlenmiştir. Spekral imza yoğunlukları grafik haline getirilerek değşimler gözlenmiştir. Örnekler, 2 günlük bir süre içerisinde farklı zamanlarda görüntülenmiştir (Tablo 1).

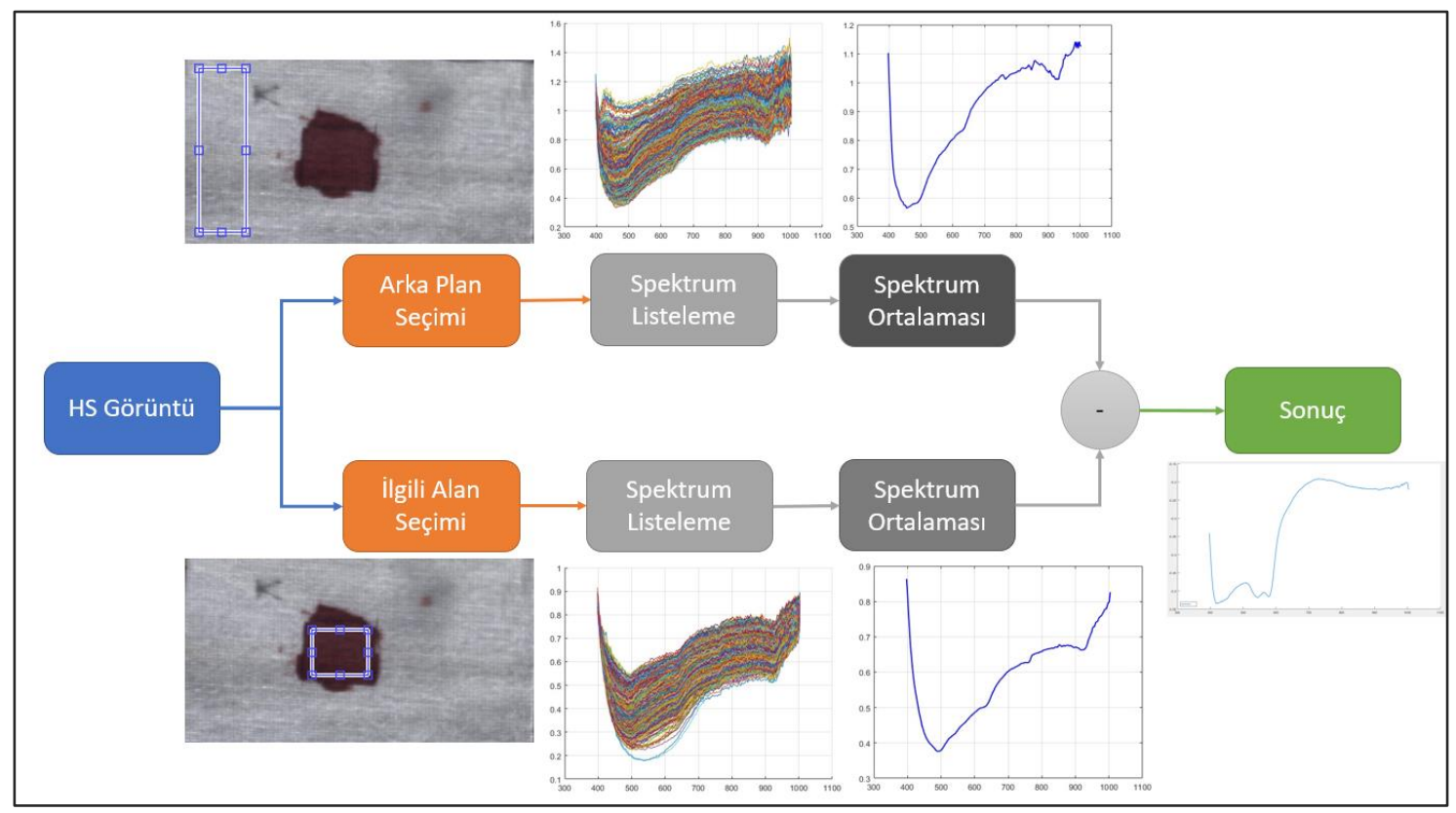

Şekil 2. Çalışmada Kullanılan Zaman Analiz, Metodu

Tablo 1. Numunelere ait görüntü alma ssatleri

\begin{tabular}{l|c}
\hline Numuneler & Görüntülenme saatleri \\
\hline \multirow{2}{*}{ Kan Örneğ $i$} & $20: 30-00: 15-12: 30-13: 30-14: 30-15: 15-$ \\
& $23: 30-20: 30$ \\
\hline \multirow{2}{*}{ Idrar Örneğ $i$} & $00: 15-12: 30-13: 30-14: 30-15: 30-23: 30-$ \\
& $20: 30$ \\
\hline Tükürük Örneğ $i$ & $20: 30-00: 15-14: 30-23: 30-20: 30$ \\
\hline
\end{tabular}

\section{Araştırma Sonuçları ve Tartışma}

Zamana bağlı değişimlerin RGB görüntüleri Şekil 3'de verilmiştir. Bu görsellerde zamana bağlı değişimin ilk evreleri belirlenebilirken zaman ilerledikçe değişim göz ile ayırt edilememektedir.

a)

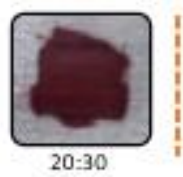

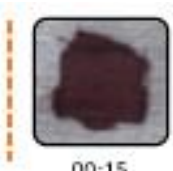

$00: 15$

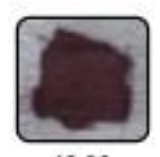

12:30

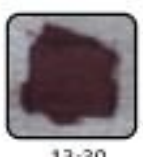

13:30

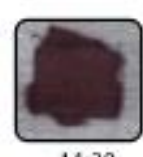

14:30

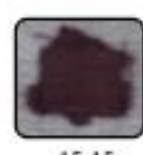

15:15

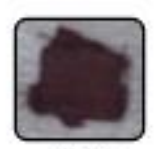

23:30

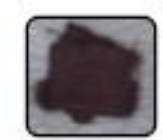

20:30

b)

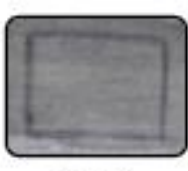

$00: 15$

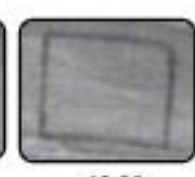

12:30

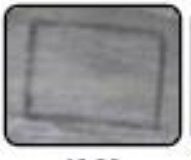

13:30

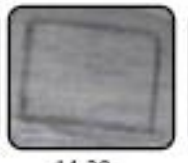

14:30

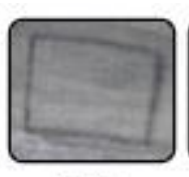

$15: 30$

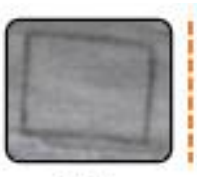

23:30

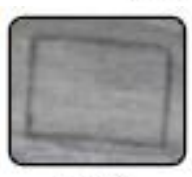

$20: 30$

C)
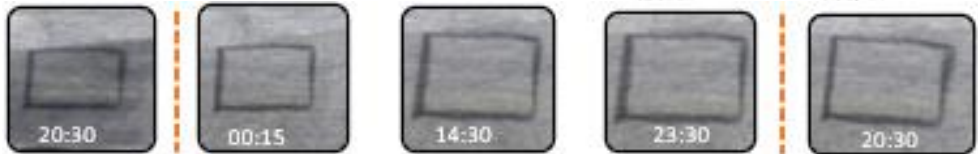

Şekil 3. Zamana bağll RGB görüntüler a) Kan Örneği, b) İdrar Örneği, c) Tükürük Örneği 


\section{European Journal of Science and Technology}

Şekil 4 incelendiğinde, saat 20:30'da beyaz kumaş üzerine damlatılan kanın zamana bağl1 spekral imza yoğunluğu görülmektedir. $\mathrm{Bu}$ grafikte yatay eksen dalga boyunu gösterirken dikey eksen spektral imza yoğunluğunu göstermektedir. 600-700nm dalga boylarında spektral imza yoğunluğu zamana bağlı olarak değişmektedir. Zaman ilerledikçe kırmızı renge ait spektrumun daha doygunlaşması sonucu spekral imza ortalamasının bu dalga boylarındaki değerleri azalmaktadır. Ayrıca kan damlası ilk damlatıldığı andaki spectral imza ile kuruduktan sonraki spectral imzaların da farklılaştığı görülmektedir (Şekil 5).

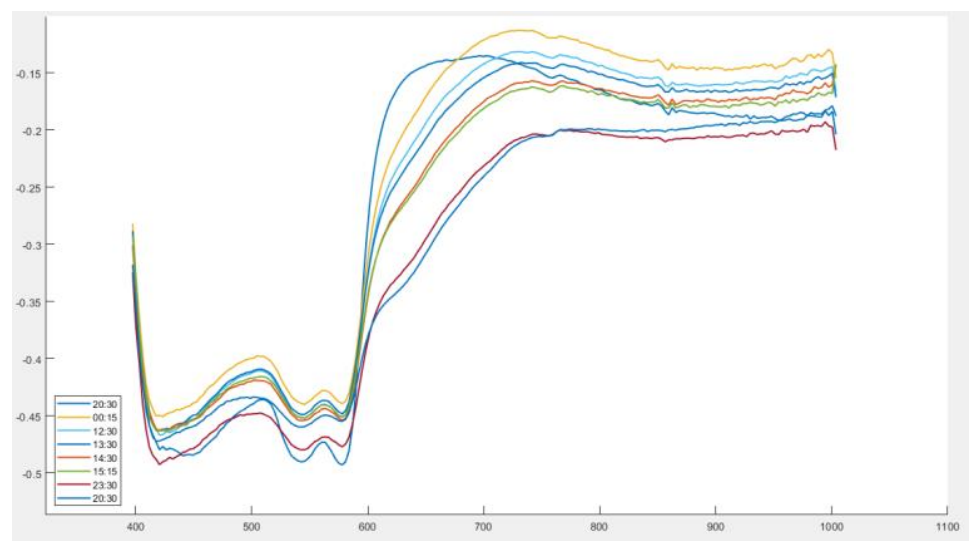

Şekil 4. Kumaşa damlatılmış kana ait zamana bağlı olarak değişim gösteren spektral imzalar

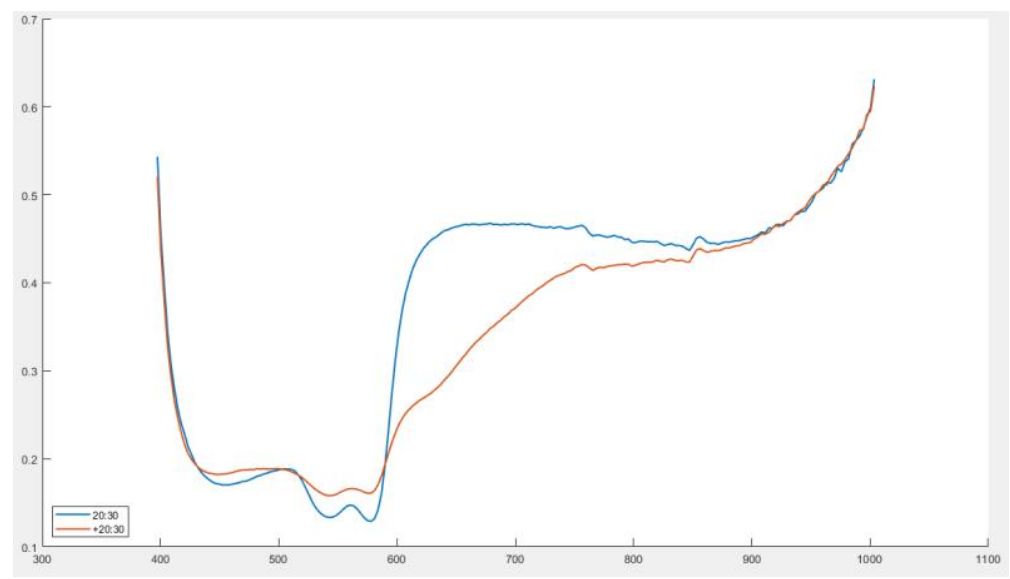

Şekil 5. Kan Örneğinin kumaşa ilk damlatıldı̆̆g hali ve son haline ait spektral imza yoğunlukları

Şekil 6 incelendiğinde kumaşa damlatılan idrarın zamana bağlı spectral imza yoğunlukları görülmektedir. Burada kan örneğinden farklı olarak spectral imzada farklılık olmazken (Şekil 7) yoğunluğundaki değişim 600-800nm dalga boylarında görülmektedir.

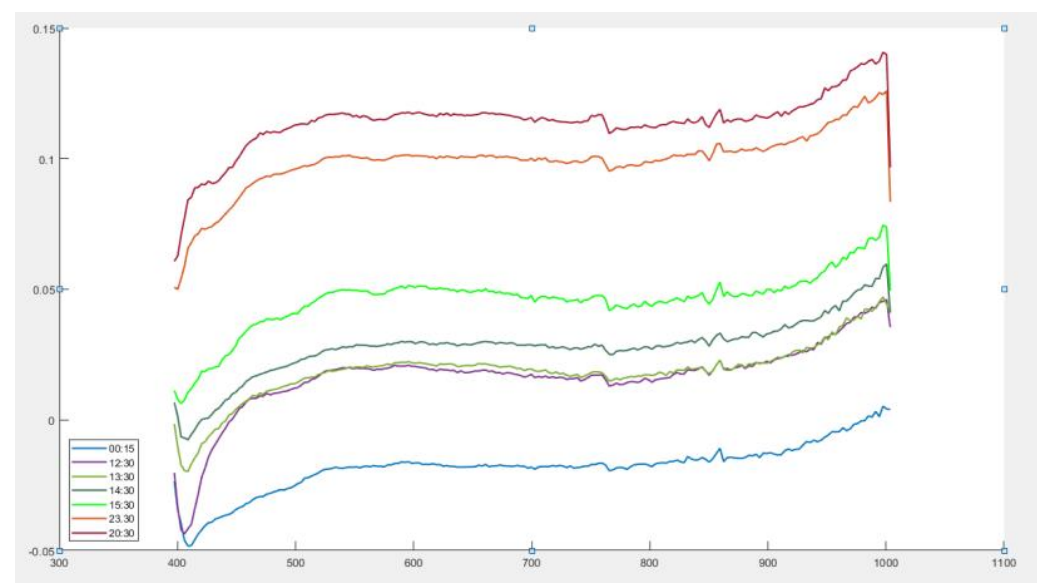

Şekil 6. Kumaşa damlatılmış idarara ait zamana bağlı olarak değişim gösteren spektral imzalar 


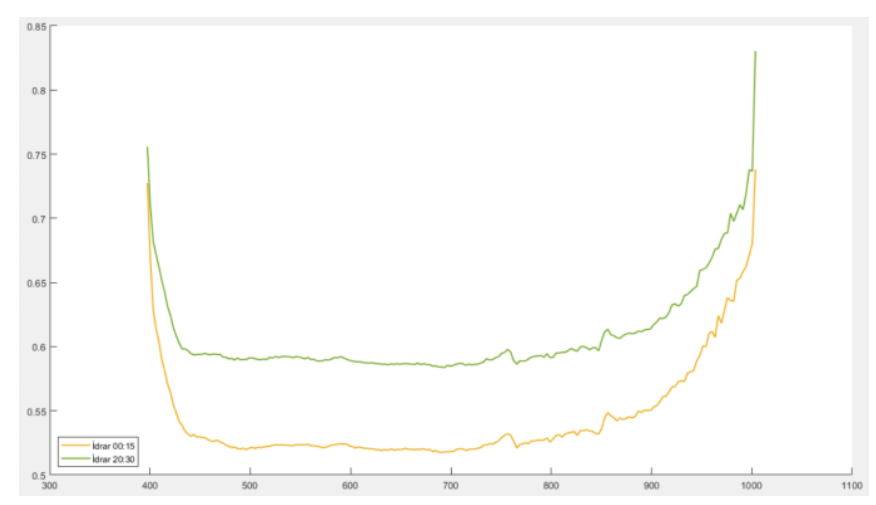

Şekil 7. İdrar Örneğinin kumaşa ilk damlatıldı̆ğ hali ve son haline ait spektral imza yoğunlukları

Şekil 8 incelendiğinde tükürük örneğinin zamana bağlı değişimi görülmektedir. Burada idrarda olduğu gibi spektral imza değişmezken, imza yoğunluğu değişmektedir. 550-800nm dalga boylarında zamana bağlı değişim görülmektedir (Şekil 9).

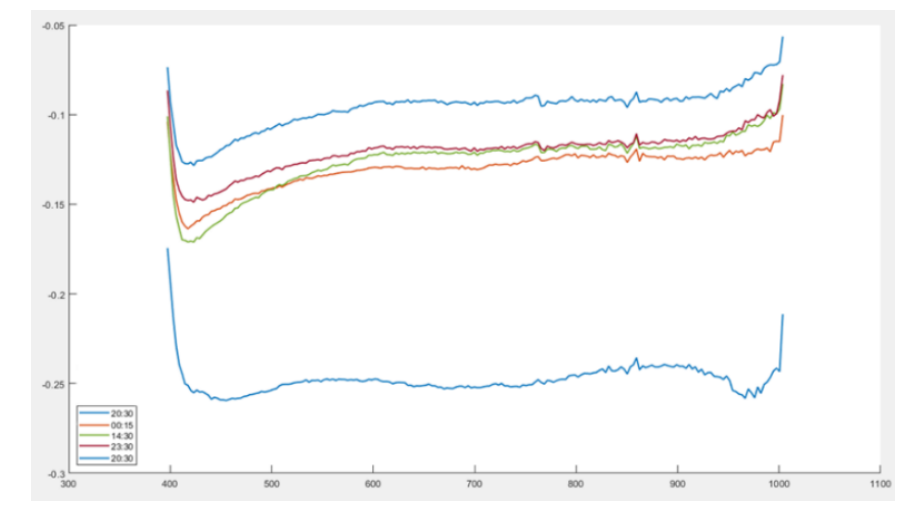

Şekil 8. Kumaşa damlatılmış tükütüğe ait zamana bağlı olarak değişim gösteren spektral imzalar

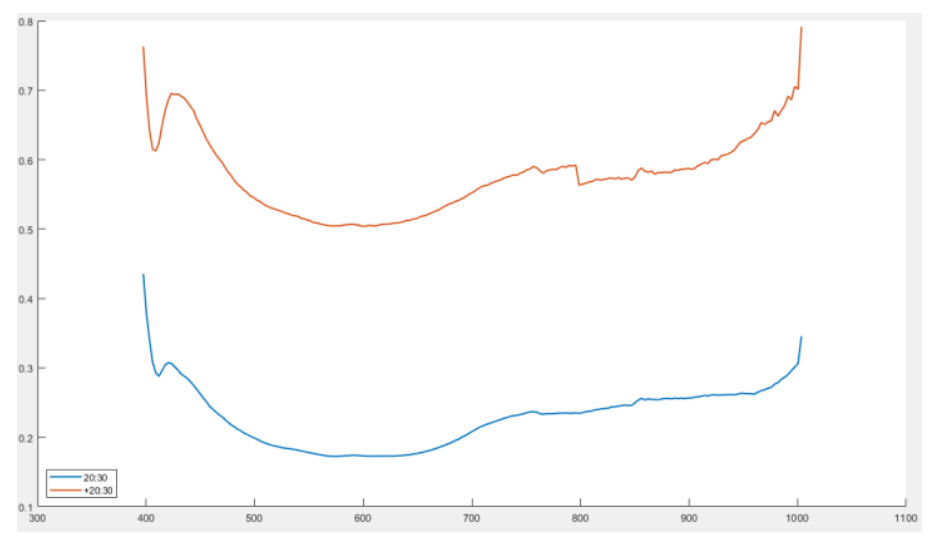

Şekil 9. Tükürük Örneğinin kumaşa ilk damlatıldı̆̆ hali ve son haline ait spektral imza yoğunlukları

Şekil 10 incelendiğinde kan, idar ve tükürük örneklerinin kumaşa damlatıldığı ilk an ve son hallerine ait spektral imza yoğunlukları görülmektedir. Burada her bir numunenin spektral imza yoğunluklarının birbirinden farklı olduğu gözlemlenmektedir. Böylece alınan numunenin spektral imzalarına bakarak hangi vücut kalıntısına ait olduğu da hiperspektral görüntüleme ile de tespit edilebilmektedir. 


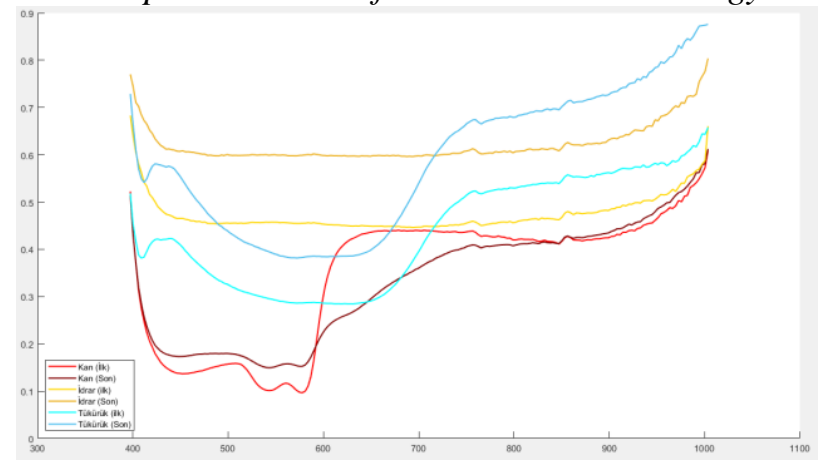

Şekil 10. Kan, idrar ve tükürüğ̈̈n kumaşa ilk damlatıldı̆̆ı hali ve son haline ait spektral imza yoğunlukları

\section{Sonuç}

Bu çalışmada adli tıp çalışanlarının olay yerine ulaştıkları anda, olay yerindeki vücut kalıntılarına ait ipuçlarını daha anlamlı hale getirilmesi hedeflenmiştir. Hiperspektral kamera ile alınan görüntünün spektral yoğunlukları oluşturulduktan sonra elde edilen grafikler incelendiğinde, kalıntılara ait imza yoğunluklarının zamana göre değiştiği saptanmıştır. Birçok alanda nesne sınıflandırması ve tespit için kullanılan hiperspektral görüntüleme yönteminin zaman değişimi ile ilgili bilgi verdiği bu çalışma ile desteklenmiştir.

Hiperspektral görüntüsü alınan numelerden kan için 600-700 nm, idrar için 600-800 nm ve tükürük için 550-800 nm dalga boylarındaki spektral imza ypğunlukları zaman bilgisini taşımaktadır. Hiperspektral görüntülemenin ne yaygın özelliği olan spektral imza tabanlı sınıflama işlemi sonrası, ilgili dalga boyları analiz edilerek vücut kalıntılarının ne olduğu ve ne zaman buşaltığına dair bilgi edinilmesi ilerleyen çalışmalarda sistematik bir şekilde çalışır hale getirilerek gerçek uygulamalar üzerinde denenecektir. Ayrıca sistem taşınabilir ve hızlı sonuçlar vereceği için adli tıp uzamnları tarafından rahatça kullanılabilecektir. Adli tıp çalışanlarının tecrübelerine destek olarak elde edilecek sonuçlar olaylara ait ipuçlarını artıracağı için daha hızlı olay çözümlemelerinin sağlanacağ düşünülmektedir. Ayrıca olay yerine ait diğer vücut kalıntıları (sperm, vücut kılı, tırnak vb.) üzerine de çalışmalar yapılarak kriminal bulguların olaya dair ipucu derinliğinin artırılması yapıalcak diğer çalışmalar için fikir niteliğindedir.

\section{Teșekkür}

Çalışmanın gerçekleştirilmesi için SPECIM IQ Mobil Hiperspektral Kamerasını tedarik eden BLG Kimya Teknolojileri Firmasına ve görüntülerin çekilmesi için uygun çalışma ortamını oluşturan Elfatek Elektronik’e teşekkür ederiz.

\section{Kaynakça}

Adam, E., Mutanga, O., Rugege, D., Multispectral and hyperspectral remote sensing for identification and mapping of wetland vegetation: a review, Wetlands Ecology and Management 18 (3) (2010) 281e296 (in English).

Afromowitz, M.A., Callis, J.B., Heimbach, D.M., DeSoto, L.A., Norton, M.K., Multispectral imaging of burn wounds: a new clinical instrument for evaluating burn depth, IEEE Transactions on Biomedical Engineering 35 (10) (1988) $842 \mathrm{e} 850$.

Carrasco, O., Gomez, R.B., Chainani, A., Roper, W.E., Hyperspectral imaging applied to medical diagnoses and food safety, in: Proc. SPIE 5097, Geo-Spatial and Temporal Image and Data Exploitation III, 2003, pp. 215e221.

Edelman, G.J., Gaston, E., Van Leeuwen, T.G., Cullen, P.J., Aalders, M.C.G., Hyperspectral imaging for non-contact analysis of forensic traces, Forensic Science International 223 (1e3) (2012) 28e39.

Edelman, G., van Leeuwen, T. G., \& Aalders, M. C. G. (2012). Hyperspectral imaging for the age estimation of blood stains at the crime scene. Forensic Science International, 223(1-3), 72-77. doi:10.1016/j.forsciint.2012.08.003

Fei, B. (2020). Hyperspectral imaging in medical applications. Hyperspectral Imaging, 523-565. doi:10.1016/b978-0-444-639776.00021-3

Feng, Y.Z., Sun, D.W., Application of hyperspectral imaging in food safety inspection and control: a review, Critical Reviews in Food Science and Nutrition 52 (11) (2012) 1039e1058 (in English).

Fischer, C., Kakoulli, I., Multispectral and hyperspectral imaging technologies in conservation: current research and potential applications, Studies in Conservation 51 (Suppl. 1) (2006) 3e16.

Govender, M., Chetty, K., Bulcock, H., A review of hyperspectral remote sensing and its application in vegetation and water resource studies, Water SA 33 (2) (2007).

Gowen, A.A., O’Donnell, C.P., Cullen, P.J., Downey, G., Frias, J.M., Hyperspectral imaging e an emerging process analytical tool for food quality and safety control, Trends in Food Science \& Technology 18 (12) (2007) 590e598.

Liang, H., Advances in multispectral and hyperspectral imaging for archaeology and art conservation, Applied Physics A 106 (2) (2012) 309e323 (in English).

Malkoff, D.B., Oliver, W.R., Hyperspectral imaging applied to forensic medicine, Proceedings of SPIE (2000) $108 \mathrm{e} 116$.

Zhao, J., Zhong, Y., Jia, T., Wang, X., Xu, Y., Shu, H., \& Zhang, L. (2018). Spectral-spatial classification of hyperspectral imagery with cooperative game. ISPRS Journal of Photogrammetry and Remote Sensing, 135, 31-42. doi:10.1016/j.isprsjprs.2017.10.006. 